- Data Description Article •

\title{
Datasets for the CMIP6 Scenario Model Intercomparison Project (ScenarioMIP) Simulations with the Coupled Model CAS FGOALS-f3-L
}

\author{
Shuwen ZHAO ${ }^{1,2}$, Yongqiang YU"1,2,3, Pengfei LIN ${ }^{1,2}$, Hailong LIU ${ }^{1,2}$, Bian $\mathrm{HE}^{1,2}$, Qing BAO ${ }^{1,2}$, \\ Yuyang GUO ${ }^{1,2}$, Lijuan $\mathrm{HUA}^{4}$, Kangjun $\mathrm{CHEN}^{1,2}$, and Xiaowei $\mathrm{WANG}^{1,2,5}$ \\ ${ }^{1}$ State Key Laboratory of Numerical Modeling for Atmospheric Sciences and Geophysical Fluid Dynamics (LASG), \\ Institute of Atmospheric Physics, Chinese Academy of Sciences, Beijing 100029, China \\ ${ }^{2}$ University of Chinese Academy of Sciences, Beijing 100049, China \\ ${ }^{3}$ Center for ocean Mega-Science, Chinese Academy of Sciences, Qingdao 266071, China \\ ${ }^{4}$ Chinese Academy of Meteorological Sciences, Beijing 100081, China \\ ${ }^{5}$ Yunnan University, Kunming 650091, China
}

(Received 17 April 2020; revised 29 August 2020; accepted 8 September 2020)

\begin{abstract}
The datasets for the tier-1 Scenario Model Intercomparison Project (ScenarioMIP) experiments from the Chinese Academy of Sciences (CAS) Flexible Global Ocean-Atmosphere-Land System model, finite-volume version 3 (CAS FGOALS-f3-L) are described in this study. ScenarioMIP is one of the core MIP experiments in phase 6 of the Coupled Model Intercomparison Project (CMIP6). Considering future $\mathrm{CO}_{2}, \mathrm{CH}_{4}, \mathrm{~N}_{2} \mathrm{O}$ and other gases' concentrations, as well as land use, the design of ScenarioMIP involves eight pathways, including two tiers (tier-1 and tier-2) of priority. Tier-1 includes four combined Shared Socioeconomic Pathways (SSPs) with radiative forcing, i.e., SSP1-2.6, SSP2-4.5, SSP3-7.0 and SSP5-8.5, in which the globally averaged radiative forcing at the top of the atmosphere around the year 2100 is approximately $2.6,4.5,7.0$ and $8.5 \mathrm{~W} \mathrm{~m}^{-2}$, respectively. This study provides an introduction to the ScenarioMIP datasets of this model, such as their storage location, sizes, variables, etc. Preliminary analysis indicates that surface air temperatures will increase by about $1.89^{\circ} \mathrm{C}, 3.07^{\circ} \mathrm{C}, 4.06^{\circ} \mathrm{C}$ and $5.17^{\circ} \mathrm{C}$ by around 2100 under these four scenarios, respectively. Meanwhile, some other key climate variables, such as sea-ice extension, precipitation, heat content, and sea level rise, also show significant long-term trends associated with the radiative forcing increases. These datasets will help us understand how the climate will change under different anthropogenic and radiative forcings.
\end{abstract}

Key words: CMIP6, ScenarioMIP, FGOALS-f3-L, coupled model, data description

Citation: Zhao, S. W., and Coauthors, 2021: Datasets for CMIP6 Scenario Model Intercomparison Project (ScenarioMIP) simulations with the coupled model CAS FGOALS-f3-L. Adv. Atmos. Sci., 38(2), 329-339, https://doi.org/10.1007/s00376020-0112-9.

\section{Introduction}

The state-of-the-art earth/climate system model is an important tool to investigate multi-sphere interaction of the climate system as well as reproduce the past climate change and project future climate change. A modeling group from the State Key Laboratory of Numerical Modeling for Atmospheric Sciences and Geophysical Fluid Dynamics (LASG), Institute of Atmospheric Physics (IAP), has been developing the Flexible Global Ocean-Atmosphere-Land System

\footnotetext{
* Corresponding author: Yongqiang YU

Email: yyq@lasg.iap.ac.cn
}

model (FGOALS) since the early 2000s (Yu et al., 2002, 2004). Its second spectral version, FGOALS-s2 (Bao et al., 2013; Zhou et al., 2014b), was released in 2012 and contributed to phase 5 of the Coupled Model Intercomparison Project (CMIP5) (Taylor et al., 2012). This model shows good simulation performance in global and regional climate characteristics, such as sea surface temperature (SST), precipitation, and atmospheric circulation. Specifically, FGOALS-s2 reproduces the annual and semi-annual SST cycles in the equatorial Pacific Ocean, the main characteristics of the Asian summer monsoon, the extratropical teleconnection patterns of large-scale climate, the irregularity of ENSO periods, etc. (Bao et al., 2013). The third version is 
FGOALS-f3-L, and has been employed to carry out many numerical experiments following the CMIP6 design (Eyring et al., 2016).

The long-term trend of deep ocean in the Pi-Control experiment of FGOALS-f3-L is smaller than that of the previous version (Guo et al, 1996), so responses of the coupled model to the external forcings in the Scenario Model Intercomparison Project (ScenarioMIP) experiment are less affected as before by long-term climate drift. This suggests that FGOALS-f3-L is more reliable in its future climate projections. In addition, model biases in the tropical region are also significantly reduced, which further narrows the uncertainty of the projected climate change.

As one of primary activities in CMIP6, ScenarioMIP will improve understanding of climate changes under different future scenarios and their impacts on society. According to the model participation information provided by the CMIP6 website (https://rawgit.com/WCRP-CMIP/CMIP6_ CVs/master/src/CMIP6_source_id.html), more than 50 models around the world have participated in the model comparison program so far. The ScenarioMIP experiments are driven by new emissions and land-use scenarios (Riahi et al., 2017), which are produced with integrated assessment models (IAMs) considering the Shared Socioeconomic Pathways (SSPs) and future pathways of societal development. The ScenarioMIP aims at: (1) facilitating integrated research in order to better understand the impact of different scenarios on the physical processes of the climate system and the impact of climate change on society; (2) providing a data basis for ScenarioMIP specific scientific issues and other CMIP6 projects, aimed at the climate impact of particular forcing relative to scenario projections; and (3) providing a basis for the development of a new method of quantitative assessment and prediction of uncertainty based on multi-model ensembles, considering model performance, model dependence and observational uncertainty (O'Neill et al., 2016; Zhang et al., 2019).

The ScenarioMIP simulations of FGOALS-f3-L were completed in October 2019 and the data have been released on the Earth System Grid Federation (ESGF) data server (https://esgf-node.llnl.gov/projects/cmip6/). To provide a description of the ScenarioMIP model outputs, we present some fundamental analysis on some key output variables, such as temperature, precipitation etc. Descriptions of the model and experimental design are documented in section 2. The projections of long-term climate change are described in section 3. And finally, section 4 provides data records and usage notes.

\section{Model and experiments}

\subsection{Model description}

The climate model CAS FGOALS-f3-L includes four individual components: an atmospheric component, version 2.2 of the Finite-volume Atmospheric Model (FAMIL) (Zhou et al., 2015; Bao et al., 2019; Li et al., 2019), which has a horizontal resolution of $1^{\circ}$ (lat) by $1.25^{\circ}$ (lon); an oceanic component, version 3 of the LASG/ IAP Climate Ocean Model (LICOM3) (Lin et al., 2020), in which the horizontal resolution is also proximately equal to $1^{\circ}$; a land component, version 4.0 of the Community Land Model (CLM4) (Oleson et al., 2010), which has a horizontal resolution of $0.9^{\circ}$ (lat) by $1.25^{\circ}$ (lon); and a sea-ice component, version 4 of the Los Alamos Sea Ice Model (CICE4) (Hunke and Lipscomb, 2010), in which the horizontal resolution is also proximately equal to $1^{\circ}$. A flux coupler module, version 7 of NCAR's coupler (Craig, 2014), is used to connect these four components.

\subsection{Experimental design}

\subsubsection{Introduction to the scenarios}

CMIP, now in its sixth phase (CMIP6), organized by the World Climate Research Programme's Working Group on Coupled Modelling, has become one of the cornerstones of climate science. ScenarioMIP, one of the major activities of CMIP6, can solve the problem raised in CMIP6 about assessing future climate changes induced by human activity.

For the first time, future scenario experiments are to be run as a MIP. The new scenarios in ScenarioMIP are based on the SSPs and forcing levels. The SSPs describe different scenarios of social development in the future without the impact of climate change or climate policies. SSP1, SSP2, SSP3, SSP4 and SSP5 represent pathways of sustainable development, middle of the road, regional rivalry, inequality, and fossil-fueled development, respectively (O'Neill et al., 2016; Zhang et al., 2019).

Considering future emissions, greenhouse gas (GHG) concentrations and particular land use, the design of ScenarioMIP involves eight pathways, including two tiers (tier-1 and tier-2) of priority. The scenarios in tier-1 are important for climate science, IAM, and IAV (impacts, adaptation and vulnerability) research, and there are four experiments in tier-1 under different forcing scenarios, named SSP1-2.6, SSP2-4.5, SSP3-7.0 and SSP5-8.5. There are other scenarios of interest, including additional 21 st century scenarios, initial condition ensemble members for the SSP3-7.0 scenario, and long-term extension scenarios. Due to the limited computer resource, only tier-1 experiments are conducted with CASFGOALS-f3-L, and thus we only describe some details of tier-1 as shown in Table 1. SSP1-2.6, SSP2-4.5 and SSP5-8.5 are updates of the previous RCP2.6, RCP4.5 and RCP8.5 in CMIP5, respectively. SSP3-7.0 is a new scenario, which represents the medium to high end of the range

Table 1. ScenarioMIP experiment designs.

\begin{tabular}{cccc}
\hline Scenario name & Forcing category & 2100 forcing $\left(\mathrm{W} \mathrm{m}^{-2}\right)$ & $\mathrm{SSP}$ \\
\hline SSP1-2.6 & Low & 2.6 & 1 \\
SSP2-4.5 & Medium & 4.5 & 2 \\
SSP3-7.0 & High & 7.0 & 3 \\
SSP5-8.5 & High & 8.5 & 5 \\
\hline
\end{tabular}


of future forcing pathways (O'Neill et al., 2016; Zhang et al., 2019). In general, ScenarioMIP's adoption of SSP pathways can provide more reliable information about climate change than before to policymakers.

\subsubsection{Experiment forcings}

Anthropogenic forcings in ScenarioMIP experiments consist of land use, emissions of long-lived GHGs, concentrations of long-lived GHGs, and emissions of air pollutants. In addition, there are some requirements for these SSP simulations as follows: The model version participating in ScenarioMIP must be identical to that participating in the CMIP6 historical run, thus ensuring continuity of climate simulation. All ScenarioMIP experiments must use the ScenarioMIPprovided concentrations for all long-lived GHGs, such as $\mathrm{CO}_{2}, \mathrm{CH}_{4}, \mathrm{~N}_{2} \mathrm{O}$ and CFCs. The concentrations of $\mathrm{CO}_{2}, \mathrm{CH}_{4}$ and $\mathrm{N}_{2} \mathrm{O}$ in our model are shown in Fig. 1, in which it can be seen that, for concentrations of $\mathrm{CH}_{4}$ and $\mathrm{N}_{2} \mathrm{O}$, the concentrations in SSP3-7.0 are higher than those in SSP5-8.5. However, this feature is not reflected in the time series of anthropogenic radiative forcing (O'Neill et al., 2016). $\mathrm{CO}_{2}$ still dominates the GHGs in the future of the 21st century. In addition, ScenarioMIP provides other anthropogenic forcings (i.e., short-lived GHGs, aerosol, and ozone), up-todate solar radiation time series (Matthes et al., 2017), and volcanic forcing prescribed in terms of historical volcanic eruptions. Moreover, as a climate system model, the coupled model CASFGOALS-f3-L is driven by concentrations of GHGs in ScenarioMIP experiments. All forcing data from CMIP6 are bilinearly interpolated into the grid points of the atmospheric component model.

\section{Projections of long-term climate change}

A portion of the ScenarioMIP datasets of the CAS FGOALS-f3-L have been submitted online. In this section, the responses of the climate system to the radiative forcings

(a)
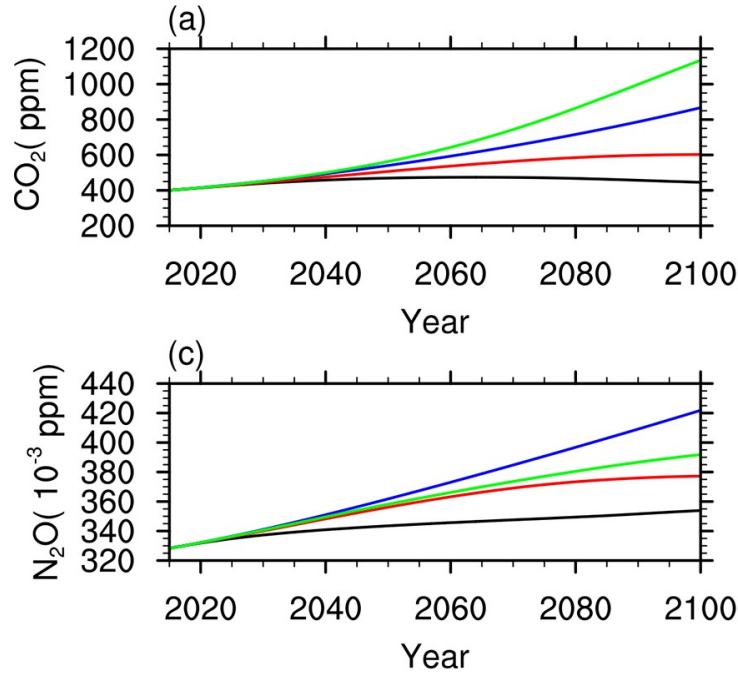

from ScenarioMIP experiments are presented.

\subsection{Temporal evolution in SSP experiments}

Figure 2 shows the annual global mean net radiation at the top of the atmosphere (TOA), surface air temperature at $2 \mathrm{~m}$, sea-ice extent in the Northern Hemisphere in September, the upper $700 \mathrm{~m}$ and 700-2000 m ocean heat content anomalies, sea level rise, and precipitation in 2015-2100, for SSP1-2.6, SSP2-4.5, SSP3-7.0 and SSP5-8.5. The upper $700 \mathrm{~m}$ and 700-2000 $\mathrm{m}$ ocean heat content anomalies are calculated relative to the 20-year mean from 1995 to 2014 in historical runs of our model. The sea level rise is calculated based on the density change relative to the 1995-2014 climatological mean state that resulted from heat expansion (Landerer et al., 2007).

The net radiation at the TOA (Fig. 2a) in the four different scenarios are positive, which means the energy of the earth system is imbalanced and increased. With gradual stabilization of GHG concentrations for SSP1-2.6 (black curves in Fig. 1), TOA net radiation presents a definite decreasing trend for SSP1-2.6 and the value is getting closer to $0.5 \mathrm{~W} \mathrm{~m}^{2}$ around 2100, revealing a quasi-stabilization characteristic. This shows that the net radiation at the TOA will gradually become balanced and a future equilibrium state will be achieved after a few centuries. Also, there is a slight upward trend of TOA net radiation during 2015-60 and a downward trend after about 2060, for SSP2-4.5. However, TOA net radiation continues to increase for SSP3-7.0 and SSP58.5 till 2100. In fact, these changes in the net TOA radiation budget basically correspond to the temporal evolution of GHG concentrations in the 21 st century in Fig. 1. However, it should be noted that the experiments are still beyond stabilization at the end of the 21st century, except for the SSP1-26 experiment, because the climate system might take a very long time (perhaps centuries) to reach a new steady state as a response to sufficiently strong external radiation forcings. The variation trend of TOA net radiation in
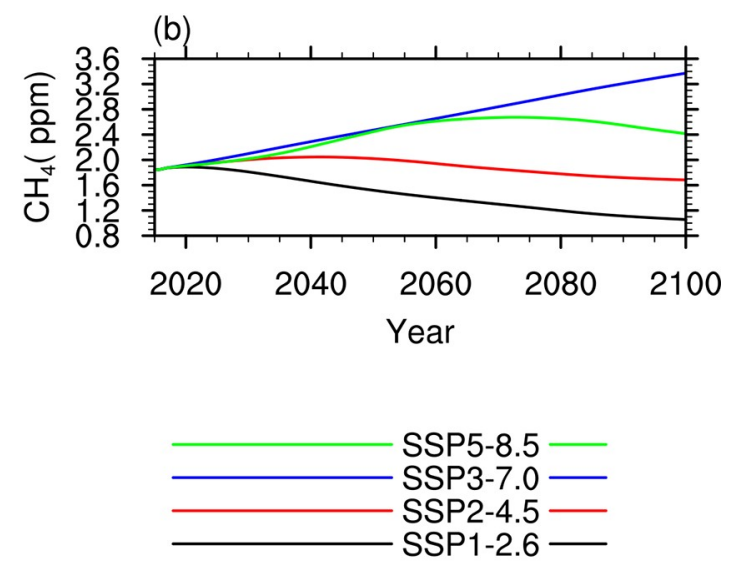

Fig. 1. Time series of (a) $\mathrm{CO}_{2}$ (units: ppm), (b) $\mathrm{CH}_{4}$ (units: ppm), and (c) $\mathrm{N}_{2} \mathrm{O}$ (units: $10^{-3}$ ppm) concentrations from 2015 to 2100 in ScenarioMIP experiments. 

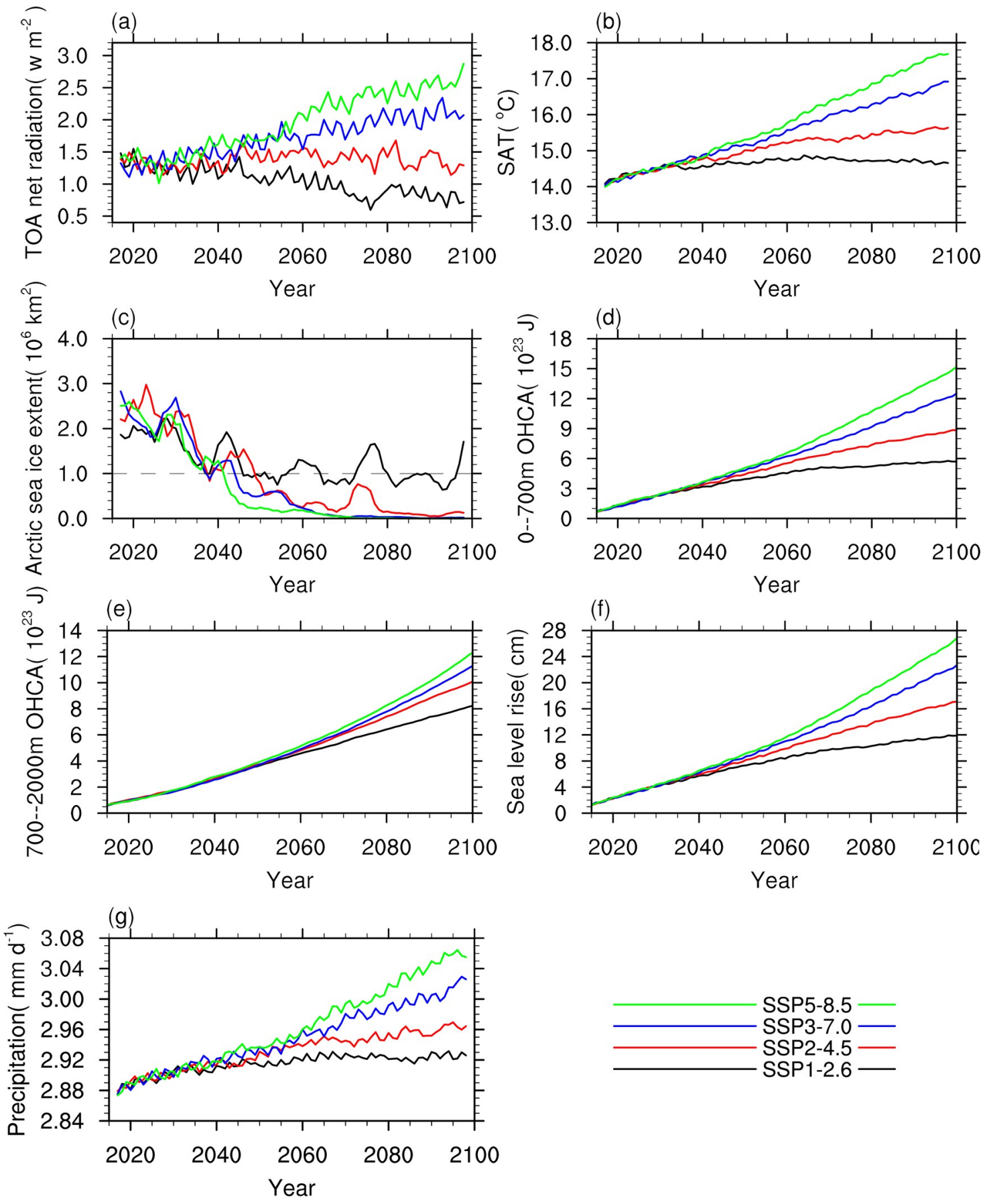

SSP5-8.5

SSP3-7.0

SSP2-4.5

SSP1-2.6

Fig. 2. The annual global mean (a) TOA net radiation (units: $\mathrm{W} \mathrm{m}^{-2}, 5$-year running mean), (b) surface air temperature at $2 \mathrm{~m}$ (SAT, units: ${ }^{\circ} \mathrm{C}, 5$-year running mean), (c) Arctic sea-ice extent (units: $10^{6} \mathrm{~km}^{2}$, 5-year running mean, dashed line represents near ice-free conditions), (d) upper $700 \mathrm{~m}$ ocean heat content anomalies relative to the 20-year mean from 1995 to 2014 in historical runs (0-700 m OHCA, units: 1023 J, annual mean), (e) 700-2000 m ocean heat content anomalies relative to the 20-year mean from 1995 to 2014 in historical runs (700-2000 m OHCA, units: $10^{23} \mathrm{~J}$, annual mean), (f) sea level rise due to heat expansion relative to the 20-year mean from 1995 to 2014 in historical runs (sea level rise, units: $\mathrm{cm}$, annual mean), and $(\mathrm{g})$ precipitation (units: $\mathrm{mm} \mathrm{d}^{-1}, 5$-year running mean) from 2015 to 2100, for SSP1-2.6, SSP2-4.5, SSP3-7.0 and SSP5-8.5.

ScenarioMIP is similar to that in CMIP5 in climate projection experiments; it is a little more than about $0.2 \mathrm{~W} \mathrm{~m}^{-2}$ above the aggregate mean of CMIP5 (Collins et al., 2013).

A significant feature of climate change is the changes of surface air temperature. It can be seen from the time series of annual global mean surface air temperature (Fig. 2b) that all four scenarios show persistent warming throughout the whole of the 21st century. Temperature increases are almost the same for all the scenarios during the first 10 years and then differ from each other after 2026. 
The warming rate is highest in SSP5-8.5, and remarkably lower in SSP1-2.6, in which the global mean surface air temperature reaches a quasi-steady state. Specifically, for SSP1-2.6, SSP2-4.5, SSP3-7.0 and SSP5-8.5, projected global mean surface air temperatures between 2080 and 2100 relative to the climatological mean between 1850 and 1900 from historical runs increase by $1.97^{\circ} \mathrm{C}, 2.84^{\circ} \mathrm{C}$, $3.91^{\circ} \mathrm{C}$ and $4.66^{\circ} \mathrm{C}$, respectively. Compared with the CMIP5 multi-model ensemble mean temperature changes, the coupled model simulates higher temperature changes (Collins et al., 2013), which should be attributable to the larger climate sensitivity of FGOALS-f3-L. The climate sensitivity of our model is about $3.0^{\circ} \mathrm{C}$ and slightly larger than the result of the CMIP5 multi-model ensemble mean (Collins et al., 2013; He et al., 2020).

In addition to temperature, the change in sea-ice extent, particularly in the Arctic, is a crucial feature of climate change. Also, September is the end of the summer melting season. The annual sea-ice extents in the Arctic in September (Fig. 2c) in SSP2-4.5, SSP3-7.0 and SSP5-8.5 exhibit downward trends and appear to have steepened with time. An ice-free summer condition is defined by an ice extent of less than $10^{6} \mathrm{~km}^{2}$ (Stroeve et al., 2012). The Arctic will be nearly ice-free in September for SSP2-4.5 after 2049, for SSP3-7.0 after 2044, and for SSP5-8.5 after 2041, which results from the strong warming. The September sea-ice extent in the Arctic shows a rapid reduction during 2015-55 and fluctuates around $10^{6} \mathrm{~km}^{2}$ for SSP1-2.6 after 2055. The September sea-ice extent in the Arctic of the CMIP5 multimodel ensemble mean decreases faster than the simulated sea-ice extent in FGOALS-f3-L. Meanwhile, in the CMIP5 RCP2.6, the September sea-ice extent in the Arctic drops to below $10^{6} \mathrm{~km}^{2}$ around 2060 and continues to decline to $0 \mathrm{~km}^{2}$. The main reason for this difference is the different pathway settings.

Not only is the increased TOA net radiation used to heat the atmosphere, but some of it is stored in the oceans. Insight into the ocean response to climate change can be gained by examining the changes of ocean heat content. The annual global mean upper $700 \mathrm{~m}$ (Fig. 2d) and 700-2000 m (Fig. 2e) ocean heat content anomalies increase for all four scenarios in 2015-2100, implying that the ocean will become warmer in response to positive forcings. When the SST increases as a result of positive forcing, the interior water masses respond to the integrated signal at the surface and then propagate down to greater depth. The differences in the upper $700 \mathrm{~m}$ ocean heat content anomalies between the four scenarios are not significant before 2040, but become more significant after 2040. The differences in the 700-2000 m ocean heat content anomalies between the four scenarios are not significant before 2050, but become more significant after 2050. Compared with the time series of surface air temperature, the results show that the deep ocean changes slowly with climate change. Based on the related calculation and analysis, the heat absorbed by the ocean accounts for about $76.4 \%, 78.9 \%, 83.6 \%$ and $84.6 \%$ of the added heat of the earth system from 2015 to 2100 for SSP1-
2.6, SSP2-4.5, SSP3-7.0 and SSP5-8.5, respectively, which means most of the increased earth energy is stored in the oceans and the proportion of the increased energy stored in the ocean increases as the positive forcing increases.

The observed sea level rise is mainly caused by thermal expansion of seawater and melting of land glaciers. Thermal expansion of seawater contributes about one third to the observed rise, while melting of land glaciers contributes the other two thirds (Cazenave and Remy, 2011). In a climate system model without a glacier component, only the contribution of thermal expansion to sea level, i.e., thermosteric sea level, can be estimated. The global mean thermosteric sea level rise between 2015 and 2100 is shown in Fig. 2f. The features of the time series of thermosteric sea level for all four scenarios are similar to the upper $700 \mathrm{~m}$ ocean heat content, which illustrates that the upper $700 \mathrm{~m}$ ocean warming is crucial to thermosteric sea level rise. For SSP1-2.6, SSP2-4.5, SSP3-7.0 and SSP5-8.5, the average thermosteric sea levels rise is $1.29,1.88,2.59$ and $3.06 \mathrm{~cm}(10 \mathrm{yr})^{-1}$, respectively. Moreover, comparing surface air temperature, heat content and sea level rise in SSP1-2.6, we find that, after 2050, the concentrations of $\mathrm{CO}_{2}$ stop increasing or decreasing, surface air temperature has warmed weakly or ground to a halt, but the deep sea is still warming and the thermosteric sea level is still rising. That means that responses of temperature in the deep ocean and thermosteric sea level to the external radiation forcing have long-term hysteretic effects-committed climate warming (Mauritsen and Pincus, 2017). Although the variation trend of thermosteric sea level of the CMIP5 ensemble mean is consistent with that of our model, the result of our model is smaller than that in CMIP5 (Collins et al., 2013).

In the context of global warming, the water vapor in the air increases and the global precipitation increases. The annual global mean precipitation (Fig. $2 \mathrm{~g}$ ) for all four scenarios is projected to increase gradually during 2015-2100. For SSP1-2.6, SSP2-4.5, SSP3-7.0 and SSP5-8.5, the precipitation in 2015 accounts for about $2.3 \%, 4.4 \%, 5.1 \%$ and $7.2 \%$, respectively, of that in 2100 . The precipitation change of the CMIP5 ensemble average by 2100 is less than that simulated by the model (Collins et al., 2013). Based on calculations and analyses, the correlation relationship between global precipitation and global temperature is positive and approximately linear. The changes in atmospheric energy balance lead to the changes in global precipitation mainly through the response of the surface temperature (Andrews et al., 2009; Bala et al., 2010). In addition, the precipitation sensitivity, i.e., the changes in the percentage of global precipitation relative to global temperature, is about $2 \%{ }^{\circ} \mathrm{C}^{-1}$ under global warming, which is roughly similar to previous estimates by Held and Soden (2006).

\subsection{Changes in surface air temperature}

The geographical distributions of surface $2 \mathrm{~m}$ air temperature change in 2081-2100 for SSP1-2.6, SSP2-4.5, SSP37.0 and SSP5-8.5 relative to the 20-year mean from 1995 to 2014 of the corresponding historical simulation are shown 


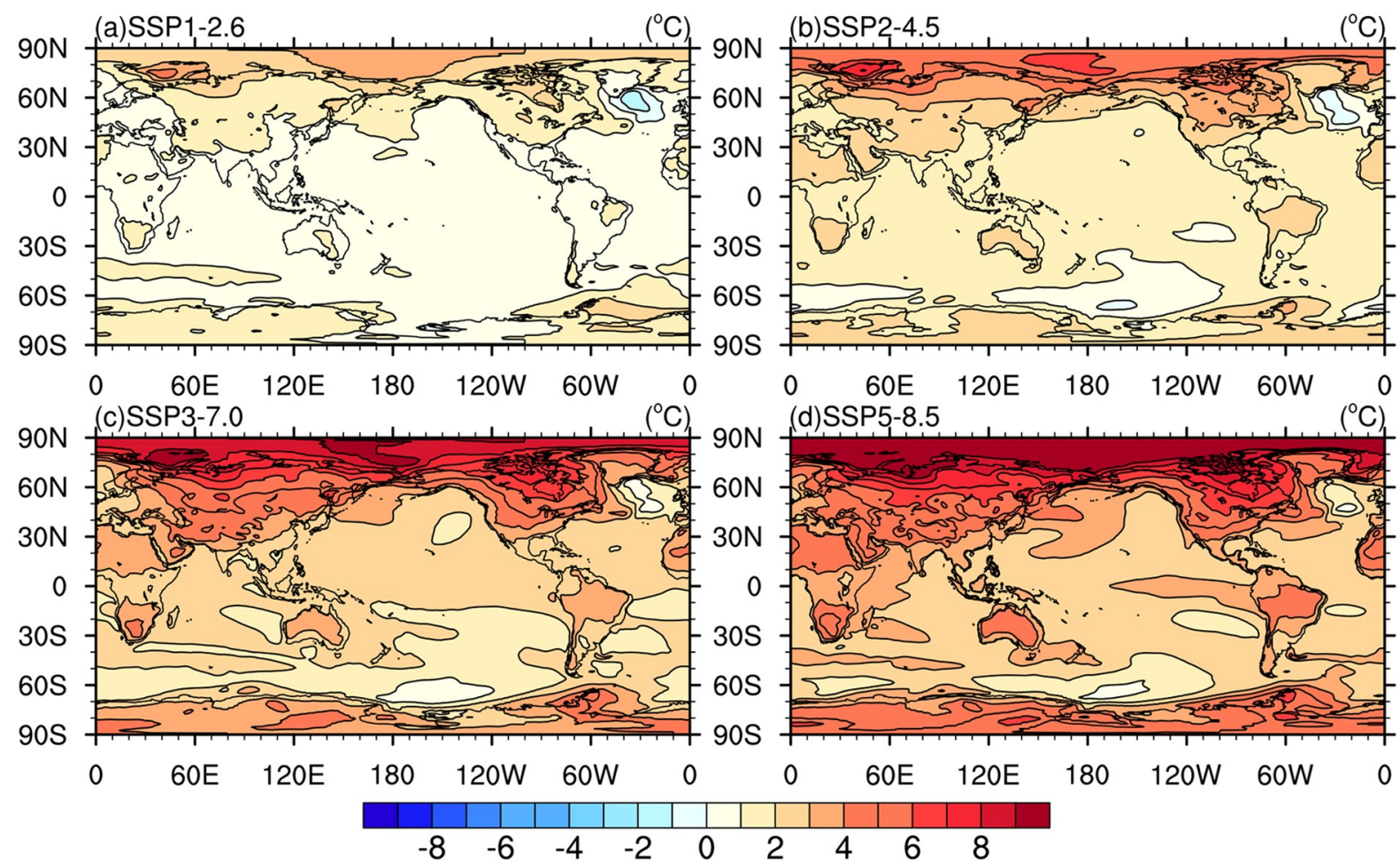

Fig. 3. Surface air temperature changes in 2080-2100 for SSP1-2.6, SSP2-4.5, SSP3-7.0 and SSP5-8.5 relative to the 20-year mean from 1995 to 2014 in historical runs (units: ${ }^{\circ} \mathrm{C}$ ).

in Fig. 3. The geographical patterns of future surface air temperature warming are similar in all four scenarios, and similar to those obtained in previous models of CMIP5, such as the polar amplification of temperature change and stronger warming over the continents (Hansen et al., 2007). Polar amplification refers to amplified surface warming in Arctic latitudes, resulting primarily from positive feedbacks from the retreat of ice and snow. The lack of polar amplification in the Antarctic is relevant to deep ocean mixing, strong heat uptake and the persistence of the vast Antarctic ice sheet. The key feature of warming is that it is larger over land areas than over oceans. The warming over all continents in the SSP1-2.6 scenario (Fig. 3a) is four to five times smaller than that in the SSP5-8.5 case (Fig. 3d), and two to three times smaller than that in the SSP2-4.5 (Fig. 3b) and SSP37.0 (Fig. 3c) experiments. The North Atlantic is slightly warmer (Figs. 3c and d) and even cooler (Figs. 3a and b), which is called the North Atlantic warming hole (NAWH) (Drijfhout et al., 2012) and is also reflected in the result of the CMIP5 ensemble mean (Collins et al., 2013). Based on previous research, it is likely that the NAWH is also related to the weakening of the Atlantic Meridional Overturning Circulation (AMOC) (Knutti et al., 2004; Timmermann et al., 2007). In addition, the NAWH is also related to warming of the tropical Indian Ocean (TIO). The rainfall related to the warming in the TIO induces a positive NAO-like response with enhanced surface westerly winds over the subpolar North Atlantic, cooling the underlying ocean via stronger turbulent heat flux and southward Ekman transport, resulting in an NAWH pattern (Hu and Fedorov, 2020, personal communication). In summary, large-scale warming patterns are very similar in all four scenarios.

\subsection{Changes in precipitation}

The geographical distributions of projected precipitation changes in 2081-2100 for SSP1-2.6, SSP2-4.5, SSP37.0 and SSP5-8.5 relative to the 20-year mean from 1995 to 2014 of the corresponding historical simulation are shown in Fig. 4. Similar to the surface $2 \mathrm{~m}$ air temperature, the changes in precipitation are smallest in SSP1-2.6 (Fig. 4a) and largest in SSP5-8.5 (Fig. 4d). Although global water vapor increases with global warming, the changes in precipitation in a warming world are not uniform across regions, which is mainly related to the regional change of atmospheric circulation and the regional increase of water vapor. Precipitation increases along the intertropical convergence zone (ITCZ), which is due to strong moisture convergence mainly associated with atmospheric circulation changes (Seager et al., 2010). The increases of water vapor coupled to the pre-existing circulation will increase the moisture convergence in the ITCZ, where there is already moisture convergence and rainfall (Stevens et al., 2013). Furthermore, through our analysis of meridional winds (not shown), the convergence intensity of meridional winds over the ITCZ region also increases; plus, the ITCZ is situated slightly southward, which should be related to the strength of the simulated meridional wind. By comparing the average precipitation of the four experiments from 2080 to 2100 with the average precipitation of the Global Precipitation Climatology 


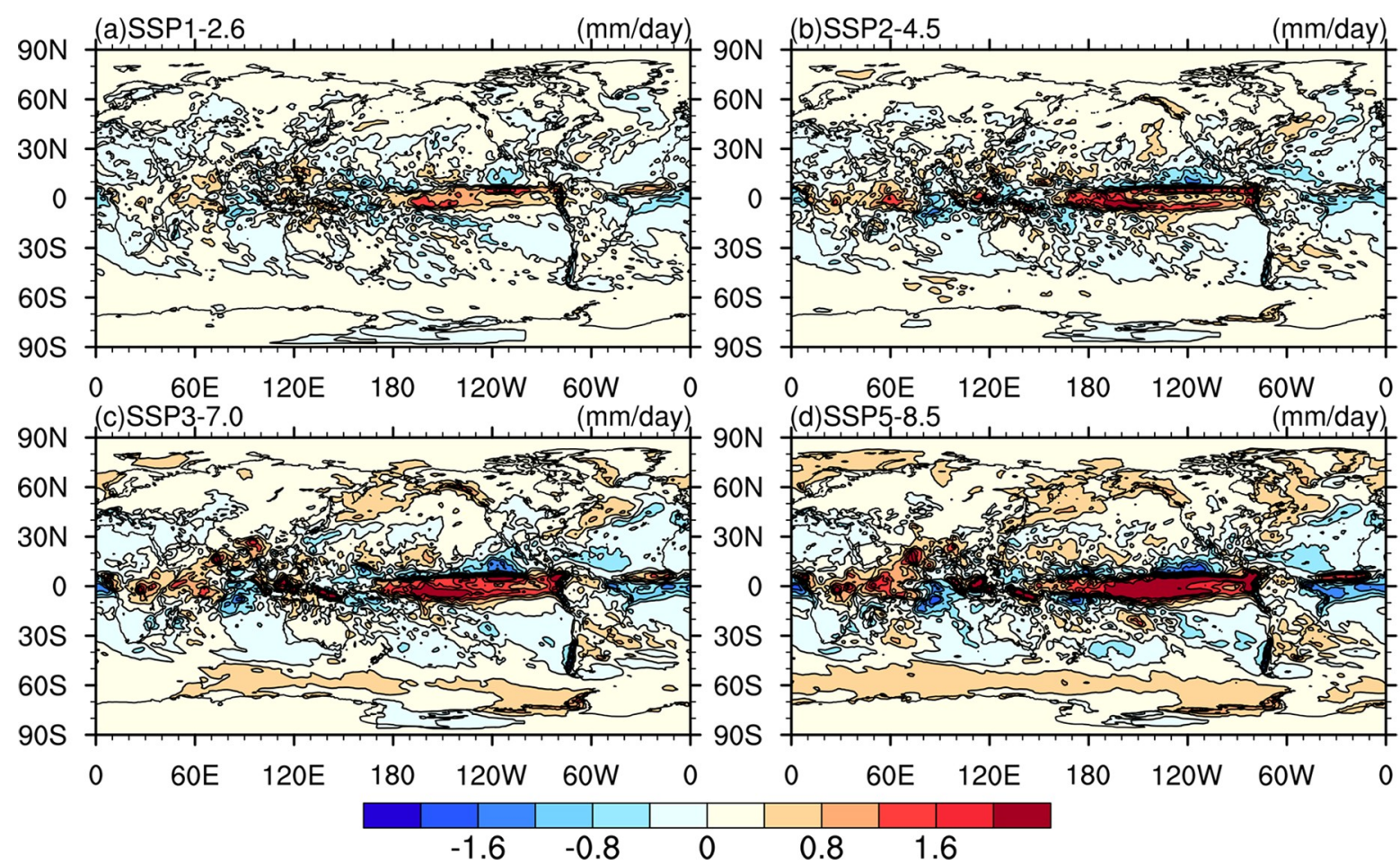

Fig. 4. Projected precipitation changes averaged between 2080 and 2100 from SSP1-2.6, SSP2-4.5, SSP3-7.0 and SSP5-8.5 simulations relative to the 20-year mean from 1995 to 2014 from historical runs (units: $\mathrm{mm} \mathrm{d}^{-1}$ ).

Project monthly precipitation dataset from 1980 to 2014 , it can be seen that the precipitation in the central and eastern equatorial Pacific Ocean increases by more than $100 \%$ in the four experiments. In addition, precipitation increases in middle and high latitudes on account of enhanced poleward transport of moisture, which is due to increased water vapor in the lower troposphere and enhanced circulation. However, precipitation decreases over much of the subtropics on account of weaker moisture transport, which is because there is a robust decrease in the difference between precipitation-minus-evaporation in these dry regions (Held and Soden, 2006; Seager et al., 2010). Specifically, precipitation increases over most of the Eurasian continent, North America, and much of South America, and precipitation decreases in the oceanic subtropics and from there into the Amazon Basin, Mediterranean, and southern regions of Africa. These features are generally similar to the results of CMIP5 (Collins et al., 2013; Nazarenko et al., 2015).

\subsection{Changes in zonally averaged ocean temperature}

The changes in zonal-mean ocean temperature for 2080-2100 under the SSP1-2.6, SSP2-4.5, SSP3-7.0 and SSP5-8.5 scenarios relative to the 20-year mean from 1995 to 2014 in historical runs are shown in Fig. 5. At the end of the 21 st century, there is a general warming above $2000 \mathrm{~m}$, while there is little change below $2000 \mathrm{~m}$ in most of the ocean. That means most of the extra energy in the ocean is stored above $2000 \mathrm{~m}$. The extra heat is gradually transferred to a greater depth of $2000 \mathrm{~m}$ through the processes of mixing and advection. In the deep sea, especially from $2000 \mathrm{~m}$ to $3000 \mathrm{~m}$, due to deep ocean mixing, the warming of the Southern Ocean is more obvious. Also, there is a slight cooling in parts of the ocean north of $20^{\circ} \mathrm{N}$ below $2000 \mathrm{~m}$, which is likely related to the projected decrease in the strength of the AMOC. Due to vertical advection directly from the surface, the descending branch of the AMOC results in a reduction in downward heat transfer and a slight cooling north of $20^{\circ} \mathrm{N}$ below $2000 \mathrm{~m}$ (Banks and Gregory, 2006).

\subsection{Summary}

If GHG emissions continue unabated, both the heat content in the ocean and the globally averaged surface air temperature will continue to rise over the 21 st century, as expected. For the four scenarios, the projected change in global mean surface air temperature relative to the climatological mean between 1850 and 1900 from historical runs is about $1.97^{\circ} \mathrm{C}, 2.84^{\circ} \mathrm{C}, 3.91^{\circ} \mathrm{C}$ and $4.66^{\circ} \mathrm{C}$, respectively, around the end of the $21 \mathrm{st}$ century. Temperature changes will not be regionally uniform, and much larger over land than ocean areas. In particular, there is polar amplification in the Arctic region. Due to this polar amplification, the sea-ice extent in the Arctic, especially in September, will significantly decrease in the coming decades. The global ocean shows continued warming under all four scenarios. The deep ocean responds slowly to the climate change. Most of the extra energy released from human activity is stored in the oceans. At the end of the 21st century, there is projected to be a general warming above $2000 \mathrm{~m}$, while there is little change below $2000 \mathrm{~m}$ in most of the ocean. However, 
(a)SSP1-2.6

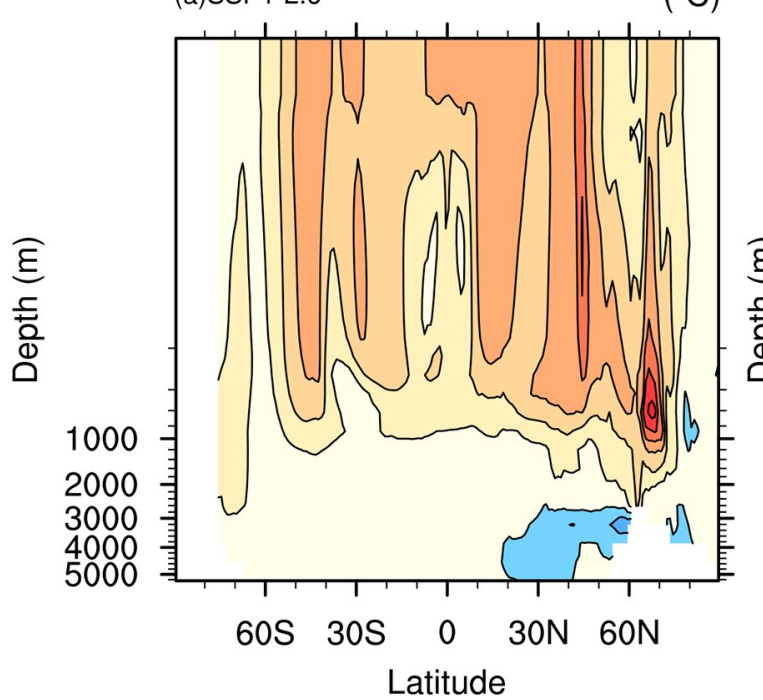

$\left({ }^{\circ} \mathrm{C}\right)$

$\left({ }^{\circ} \mathrm{C}\right)$
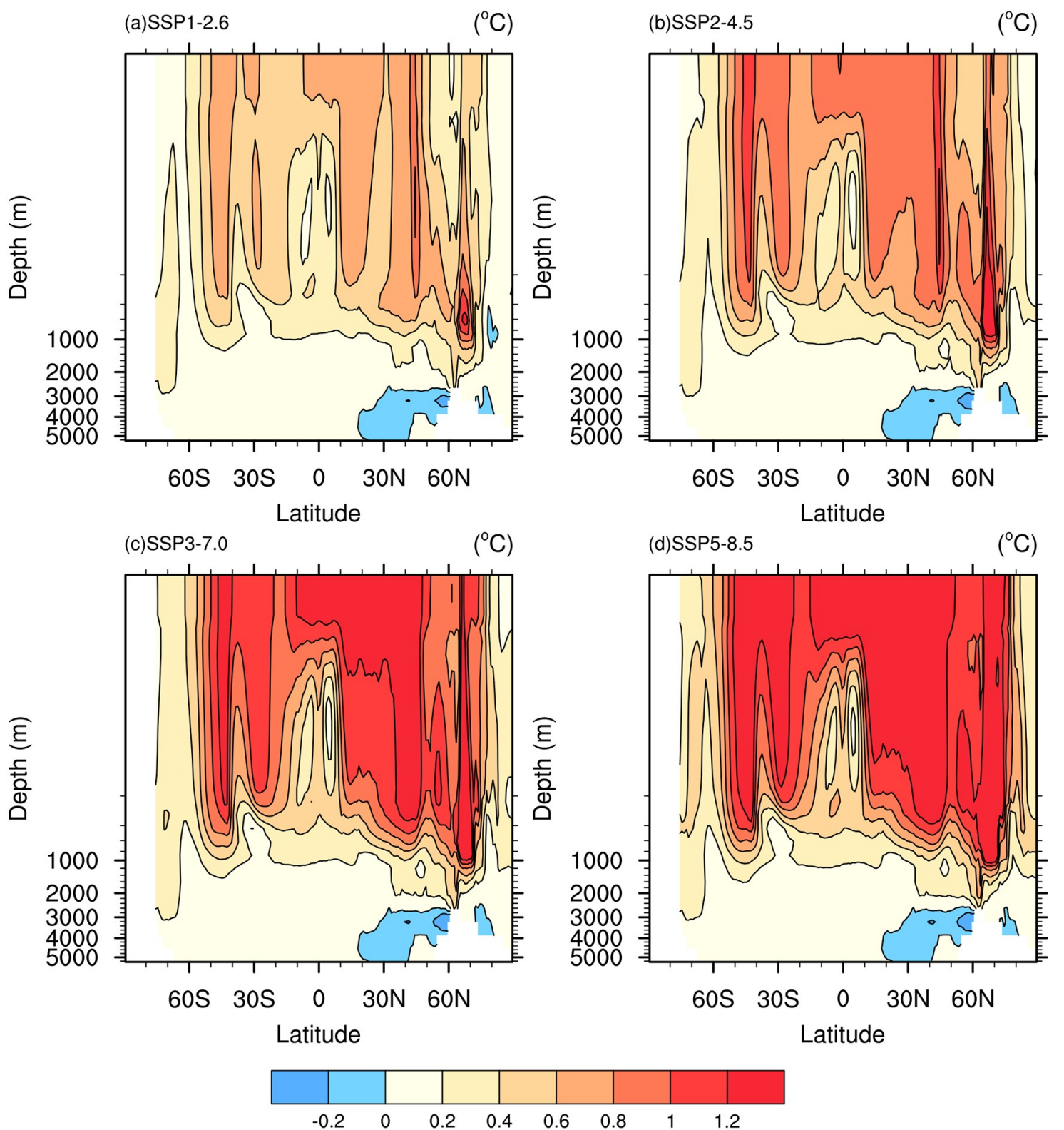

Fig. 5. Changes in zonal mean temperature in the ocean for 2080-2100 under the SSP1-2.6, SSP2-4.5, SSP3-7.0 and SSP5-8.5 scenarios relative to the 20-year mean from 1995 to 2014 in historical runs (units: ${ }^{\circ} \mathrm{C}$ ).

warming of the Southern Ocean is also evident below 2000 $\mathrm{m}$. Due to global ocean warming, the global mean thermosteric sea level rises under all four scenarios. Global mean precipitation will also increase with increased global mean surface temperature in the future 21 st century. In addition to changes in long-term trends and climatological mean states, the response of internal climate variability, such as ENSO, to global warming is another hot topic. In fact, preliminary analysis shows that ENSO amplitudes in ScenarioMIP are lightly larger than those in the piControl and historical runs, but there are no significant changes in ENSO frequency among these experiments. In future work, detailed dynamical feedback analyses of the ENSO cycle are required to explain the changes in ENSO behavior as a result of global warming.

In general, the projected climate changes from CMIP6 simulations by FGOALS-f3-L are qualitatively consistent with CMIP5 simulations by FGOALS-s2, with only some quantitative results that are slightly different. Based on the abrupt four times $\mathrm{CO}_{2}$ experiments, the estimated climate sensitivity has been reduced from $4.5^{\circ} \mathrm{C}$ in FGOALS-s2 to $3.0^{\circ} \mathrm{C}$ in FGOALS-f3-L due to changes in some subgrid parametrization schemes (He et al., 2020). As a result, the projected global mean surface air temperature by FGOALS-s2 RCP8.5 experiments, about $5.3^{\circ} \mathrm{C}$, is much larger than that of about $4.66^{\circ} \mathrm{C}$ by FGOALS-f3-L SSP5-8.5 experiments. Compared with the spatial distributions of surface air temperature from these two models under the high GHG emis- 
sions scenario, the simulated cold anomalies in the North Atlantic and the Southern Ocean, and the simulated warm anomalies of the Southern Ocean in FGOASL-s2, are larger than those in FGOASL-f3-L, which might be partly related to changes in thermohaline circulations in the deep ocean. In addition, under different GHG emission pathways, the maxima of different models appear at different locations (Zhou et al., 2014a). The difference in quantitative results may be resulted from differences in the pathways between CMIP5 and CMIP6, climate sensitivities, and the climatological mean climatology simulated by these two models, but the detailed mechanisms still need to be further analyzed.

\section{Data records and usage notes}

Four datasets of four scenarios (SSP1-2.6, SSP2-4.5,
SSP3-7.0 and SSP5-8.5) have been submitted to the ESGF node and are available at https://esgf-node.llnl.gov/search/ cmip6/. These datasets have been post-processed by version 3 of the Climate Model Output Rewriter software (CMOR3, https://cmor.llnl.gov/). The dataset format is version 4 of the Network Common Data Form (NetCDF), which is easy to read and written by professional common software such as Climate Data Operators (CDO, https://www. unidata.ucar.edu/software/netcdf/workshops/mostrecent/third_party/CDO.html), NCAR Command Language (NCL, http://www.ncl.ucar.edu), NetCDF Operator (NCO, http://nco.sourceforge.net) and Python (https://www.python. org).

All variables are uploaded to the ESGF node with their original grid, except for atmospheric variables, in which the original grid in cube-sphere form has been interpolated into a global latitude-longitude grid. The oceanic model outputs are on a tripolar grid with 30 vertical levels. The atmo-

Table 2. Descriptions of common monthly variables in ScenarioMIP datasets of CAS FGOALS-f3-L. Horizontal resolution: $1^{\circ}$ (lat) $\times$ $1.25^{\circ}$ (lon) (atmosphere); $1^{\circ} \times 1^{\circ}$ (ocean, sea ice); $0.9^{\circ}$ (lat) $\times 1.25^{\circ}$ (lon)(land)

\begin{tabular}{|c|c|c|}
\hline Variable abbreviation & Long name & units \\
\hline clt & Total cloud cover percentage & $\%$ \\
\hline evspsblsoi & Water evaporation from soil & $\mathrm{kg} \mathrm{m}^{-2} \mathrm{~s}^{-1}$ \\
\hline evspsblveg & Evaporation from canopy & $\mathrm{kg} \mathrm{m}^{-2} \mathrm{~s}^{-1}$ \\
\hline hfbasin & Northward ocean heat transport & $\mathrm{W}$ \\
\hline hfds & Downward heat flux at seawater surface & $\mathrm{W} \mathrm{m}^{-2}$ \\
\hline hur & Relative humidity & $\%$ \\
\hline hurs & Near-surface relative humidity & $\%$ \\
\hline hus & Specific humidity & 1 \\
\hline huss & Near-surface specific humidity & 1 \\
\hline mlotst & Ocean mixed layer thickness defined by sigma $\mathrm{T}$ & $\mathrm{m}$ \\
\hline mrfso & Soil frozen water content & $\mathrm{kg} \mathrm{m}^{-2}$ \\
\hline mrro & Total runoff & $\mathrm{kg} \mathrm{m}^{-2} \mathrm{~s}^{-1}$ \\
\hline mrros & Surface runoff & $\mathrm{kg} \mathrm{m}^{-2} \mathrm{~s}^{-1}$ \\
\hline mrso & Total soil moisture content & $\mathrm{kg} \mathrm{m}^{-2}$ \\
\hline mrsos & Moisture in upper portion of soil column & $\mathrm{kg} \mathrm{m}^{-2}$ \\
\hline msftbarot & Ocean barotropic mass streamfunction & $\mathrm{kg} \mathrm{s}^{-1}$ \\
\hline msftmz & Ocean meridional overturning mass streamfunction & $\mathrm{kg} \mathrm{s}^{-1}$ \\
\hline msftmzmpa & Ocean meridional overturning mass streamfunction due to parameterized mesoscale advection & $\mathrm{kg} \mathrm{s}^{-1}$ \\
\hline $\mathrm{pr}$ & Precipitation & $\mathrm{kg} \mathrm{m}^{-2} \mathrm{~s}^{-1}$ \\
\hline prsn & Snowfall flux & $\mathrm{kg} \mathrm{m}^{-2} \mathrm{~s}^{-1}$ \\
\hline prveg & Precipitation onto canopy & $\mathrm{kg} \mathrm{m}^{-2} \mathrm{~s}^{-1}$ \\
\hline psl & Sea level pressure & $\mathrm{Pa}$ \\
\hline ps & Surface air pressure & $\mathrm{Pa}$ \\
\hline sfcWind & Near-surface wind speed & $\mathrm{m} \mathrm{s}^{-1}$ \\
\hline siconc & Sea-ice area percentage (ocean grid) & $\%$ \\
\hline siconca & Sea-ice area percentage (atmospheric grid) & $\%$ \\
\hline sipr & Rainfall rate over sea ice & $\mathrm{kg} \mathrm{m}^{-2} \mathrm{~s}^{-1}$ \\
\hline sisnconc & Snow area percentage & $\%$ \\
\hline sisnthick & Snow thickness & $\mathrm{m}$ \\
\hline siu & $\mathrm{X}$-component of sea-ice velocity & $\mathrm{m} \mathrm{s}^{-1}$ \\
\hline $\operatorname{siv}$ & Y-component of sea-ice velocity & $\mathrm{m} \mathrm{s}^{-1}$ \\
\hline $\operatorname{sos}$ & Sea surface salinity & 0.001 \\
\hline rlut & TOA outgoing longwave radiation & $\mathrm{W} \mathrm{m}^{-2}$ \\
\hline rsdt & TOA incident shortwave radiation & $\mathrm{W} \mathrm{m}^{-2}$ \\
\hline
\end{tabular}


Table 2. (Continued.)

\begin{tabular}{|c|c|c|}
\hline Variable abbreviation & Long name & units \\
\hline rsut & TOA outgoing shortwave radiation & $\mathrm{W} \mathrm{m}^{-2}$ \\
\hline ta & Air temperature & K \\
\hline $\operatorname{tas}$ & Near-surface air temperature & $\mathrm{K}$ \\
\hline tauu & Surface downward eastward wind stress & $\mathrm{Pa}$ \\
\hline tauv & Surface downward northward wind stress & $\mathrm{Pa}$ \\
\hline ts & Surface temperature & K \\
\hline tsl & Temperature of soil & $\mathrm{K}$ \\
\hline thetao & Seawater potential temperature & ${ }^{\circ} \mathrm{C}$ \\
\hline thetaoga & Global average seawater potential temperature & ${ }^{\circ} \mathrm{C}$ \\
\hline tob & Seawater potential temperature at sea floor & ${ }^{\circ} \mathrm{C}$ \\
\hline tos & Sea surface temperature & ${ }^{\circ} \mathrm{C}$ \\
\hline tosga & Global average sea surface temperature & ${ }^{\circ} \mathrm{C}$ \\
\hline uas & Eastward near-surface wind & $\mathrm{m} \mathrm{s}^{-1}$ \\
\hline uo & Seawater $X$ velocity & $\mathrm{m} \mathrm{s}^{-1}$ \\
\hline vas & Northward near-surface wind & $\mathrm{m} \mathrm{s}^{-1}$ \\
\hline vo & Seawater Y velocity & $\mathrm{m} \mathrm{s}^{-1}$ \\
\hline wap & Omega $(=\mathrm{dp} / \mathrm{dt})$ & $\mathrm{Pa} \mathrm{s}^{-1}$ \\
\hline wfo & Water flux into seawater & $\mathrm{kg} \mathrm{m}^{-2} \mathrm{~s}^{-1}$ \\
\hline $\mathrm{zg}$ & Geopotential height & $\mathrm{m}$ \\
\hline zos & Sea surface height above geoid & $\mathrm{m}$ \\
\hline
\end{tabular}

spheric model outputs are on a global latitude-longitude grid with 32 vertical levels. Please refer to section 2.1 for horizontal resolution. The 125 variables of the four scenarios, such as SST, sea water salinity, sea water potential temperature, sea surface height above geoid, and so on, are available. In addition, in the ScenarioMIP experiments, a large number of high-frequency outputs are added, such as $3 \mathrm{~h}, 6$ $\mathrm{h}$, etc., which can be directly used to drive regional climate models for dynamic or statistical downscaling. The most frequently used monthly variables are listed in Table 2. Scalar data in the dataset can be interpolated directly, while vector data need to be rotated according to the angles between the original grid and the latitude-longitude grid before interpolation. If users need other related data variables, please feel free to contact us.

Acknowledgements. This study was jointly supported by the Strategic Priority Research Program of the Chinese Academy of Sciences (Grant Nos. XDA19060102 and XDB42000000) and the National Natural Science Foundation of China (Grants Nos. 41530426 and 91958201).The authors acknowledge the technical support from the National Key Scientific and Technological Infrastructure project "Earth System Science Numerical Simulator Facility " (EarthLab).

\section{Disclosure statement}

No potential conflict of interest was reported by the authors.

Open Access This article is distributed under the terms of the Creative Commons Attribution 4.0 International License (http://creativecommons.org/licenses/by/4.0/), which permits unrestricted use, distribution, and reproduction in any medium, provided you give appropriate credit to the original author(s) and the source, provide a link to the Creative Commons license, and indicate if changes were made.

\section{REFERENCES}

Andrews, T., P. M. Forster, and J. M. Gregory, 2009: A surface energy perspective on climate change. J. Climate, 22, 2557-2570, https://doi.org/10.1175/2008JCLI2759.1.

Bala, G., K. Caldeira, and R. Nemani, 2010: Fast versus slow response in climate change: Implications for the global hydrological cycle. Climate Dyn., 35, 423-434, https://doi.org/ 10.1007/s00382-009-0583-y.

Banks, H. T., and J. M. Gregory, 2006: Mechanisms of ocean heat uptake in a coupled climate model and the implications for tracer based predictions of ocean heat uptake. Geophys. Res. Lett., 33, L07608, https://doi.org/10.1029/2005GL 025352.

Bao, Q., and Coauthors, 2013: The flexible global ocean-atmosphere-land system model, spectral version 2: FGOALS-s2. Adv. Atmos. Sci., 30, 561-576, https://doi.org/10.1007/s00 376-012-2113-9.

Bao, Q., X. F. Wu, J. X. Li, L. Wang, B. He, X. C. Wang, Y. M. Liu, and G. X. Wu, 2019: Outlook for El Niño and the Indian Ocean Dipole in autumn-winter 2018-2019. Chinese Science Bulletin, 64, 73-78, https://doi.org/10.1360/N97 2018-00913. (in Chinese)

Cazenave, A., and F. Remy, 2011: Sea level and climate: Measurements and causes of changes. WIREs Climate Change, 2, 647-662, https://doi.org/10.1002/wcc.139.

Collins, M., and Coauthors, 2013: Long-term climate change: Projections, commitments and irreversibility. Climate Change 2013: The Physical Science Basis. Contribution of Working Group I to the Fifth Assessment Report of the Intergovernmental Panel on Climate Change, T. F. Stocker et al., Eds., Cambridge University Press. 1029-1136.

Craig, T., 2014: CPL7 User's Guide. [Available online from www.cesm.ucar.edu/models/cesm1.2/cpl7/doc/book1.html] 
Drijfhout, S., G. J. van Oldenborgh, and A. Cimatoribus, 2012: Is a decline of AMOC causing the warming hole above the North Atlantic in observed and modeled warming patterns? J. Climate, 25(24), 8373-8379, https://doi.org/10.1175/JCLID-12-00490.1.

Eyring, V., S. Bony, G. A. Meeh, C. A. Senior, B. Stevens, R. J. Stouffer, and K. E. Taylor, 2016: Overview of the Coupled Model Intercomparison Project Phase 6 (CMIP6) experimental design and organization. Geoscientific Model Development, 9(5), 1937-1958, https://doi.org/10.5194/gmd-91937-2016.

Guo, Y. F., Y. Q. Yu, K. M. Chen, X. Z. Jin, and X. H. Zhang, 1996: Mean climate state simulated by a coupled ocean-atmosphere general circulation model. Theor. Appl. Climatol., 55, 99-111, https://doi.org/10.1007/BF00864705.

Hansen, J., and Coauthors, 2007: Dangerous human-made interference with climate: A GISS modelE study. Atmospheric Chemistry and Physics, 7, 2287-2312, https://doi.org/10.5194/acp7-2287-2007.

He, B., and Coauthors, 2020: CAS FGOALS-f3-L model dataset descriptions for CMIP6 DECK experiments. Atmos. Ocean. Sci. Lett., https://doi.org/10.1080/16742834.2020.1778419.

Held, I. M., and B. J. Soden, 2006: Robust responses of the hydrological cycle to global warming. J. Climate, 19, 5686-5699, https://doi.org/10.1175/JCLI3990.1.

Hunke, E. C., and W. H. Lipscomb, 2010: CICE: The Los Alamos Sea ice model documentation and software user's manual version 4.1. Tech. Rep. LA-CC-06-012, 675 pp.

Knutti, R., J. Flückiger, T. F. Stocker, and A. Timmermann, 2004: Strong hemispheric coupling of glacial climate through freshwater discharge and ocean circulation. Nature, 430, 851-856, https://doi.org/10.1038/nature02786.

Landerer, F. W., J. H. Jungclaus, and J. Marotzke, 2007: Regional dynamic and steric sea level change in response to the IPCC-A1B scenario. J. Phys. Oceanogr., 37, 296-312, https://doi.org/10.1175/JPO3013.1.

Li, J. X., Q. Bao, Y. M. Liu, G. X. Wu, L. Wang, B. He, X. C. Wang, and J. D. Li, 2019: Evaluation of FAMIL2 in simulating the climatology and seasonal-to-interannual variability of tropical cyclone characteristics. Journal of Advances in Modeling Earth Systems, 11, 1117-1136, https://doi.org/ 10.1029/2018MS001506.

Lin, P. F., and Coauthors, 2020: LICOM model datasets for the CMIP6 ocean model intercomparison project. Adv. Atmos. Sci., 37, 239-249, https://doi.org/10.1007/s00376-019-92085.

Matthes, K., and Coauthors, 2017: Solar forcing for CMIP6 (v3.2). Geoscientific Model Development, 10, 2247-2302, https://doi.org/10.5194/gmd-10-2247-2017.

Mauritsen, T., and R. Pincus, 2017: Committed warming inferred from observations. Nature Climate Change, 7, 652-655, https://doi.org/10.1038/nclimate3357.

Nazarenko, L., and Coauthors, 2015: Future climate change under RCP emission scenarios with GISS ModelE2. Journal of Advances in Modeling Earth Systems, 7, 244-267, https://doi.org/10.1002/2014MS000403.

O'Neill, B. C., and Coauthors, 2016: The Scenario Model Intercomparison Project (ScenarioMIP) for CMIP6. Geoscientific Model Development, 9(9), 3461-3482, https://doi.org/10. 5194/gmd-9-3461-2016.

Oleson, K. W., and Coauthors, 2010: Technical description of version 4.0 of the community land model (CLM). NCAR/TN478+STR, $173 \mathrm{pp}$.

Riahi, K., and Coauthors, 2017: The Shared Socioeconomic Pathways and their energy, land use, and greenhouse gas emissions implications: An overview. Global Environmental Change, 42, 153-168, https://doi.org/10.1016/j.gloenvcha. 2016.05.009.

Seager, R., N. Naik, and G. A. Vecchi, 2010: Thermodynamic and dynamic mechanisms for large-scale changes in the hydrological cycle in response to global warming. J. Climate, 23, 4651-4668, https://doi.org/10.1175/2010JCLI3655.1.

Stevens, B., and Coauthors, 2013: Atmospheric component of the MPI-M Earth system model: ECHAM6. Journal of Advances in Modeling Earth Systems, 5, 146-172, https://doi.org/10.1002/jame.20015.

Stroeve, J. C., V. Kattsov, A. Barrett, M. Serreze, T. Pavlova, M. Holland, and W. N. Meier, 2012: Trends in Arctic sea ice extent from CMIP5, CMIP3 and observations. Geophys. Res. Lett., 39, L16502, https://doi.org/10.1029/2012GL 052676.

Taylor, K. E., R. J. Stouffer, and G. A. Meehl, 2012: An overview of CMIP5 and the experiment design. Bull. Amer. Meteor. Soc., 93, 485-498, https://doi.org/10.1175/BAMS-D11-00094.1.

Timmermann, A., and Coauthors, 2007: The influence of a weakening of the Atlantic meridional overturning circulation on ENSO. J. Climate, 20, 4899-4919, https://doi.org/10.1175/ JCLI4283.1.

Yu, Y. Q., R. C. Yu, X. H. Zhang, and H. L. Liu, 2002: A flexible global coupled ocean-atmospheric general circulation model. Adv. Atmos. Sci., 19, 169-190, https://doi.org/10. 1007/s00376-002-0042-8.

Yu, Y.Q., X.H Zhang. and Y.F Guo, 2004: Global coupled ocean-atmosphere general circulation models in LASG/IAP. Adv. Atmos. Sci., 21, 444-455, https://doi.org/10.1007/BF 02915571.

Zhang, L. X., X. L. Chen, and X. G. Xin, 2019: Short commentary on CMIP6 Scenario Model Intercomparison Project (ScenarioMIP). Climate Change Research, 15, 519-525, https://doi.org/10.12006/j.issn.1673-1719.2019.082. (in Chinese)

Zhou, L. J., and Coauthors, 2015: Global energy and water balance: Characteristics from finite-volume Atmospheric Model of the IAP/LASG (FAMIL1). Journal of Advances in Modeling Earth Systems, 7, 1-20, https://doi.org/10.1002/ 2014MS000349.

Zhou, T. J., and F. F. Song, 2014a: Representative Concentration Pathway (RCP) projection of climate change by FGOALS. Flexible Global Ocean-Atmosphere-Land System Model, T. J. Zhou, Y. Q. Yu, Y. Liu, and B. Wang, Eds., Springer, 267-274, https://doi.org/10.1007/978-3-642-41801-3_32.

Zhou, T. J., L. W. Zou, B. Wu, C. X. Jin, F. F. Song, X. L. Chen, and L. X. Zhang, 2014b: Development of earth/climate system models in China: A review from the coupled model intercomparison project perspective. Journal of Meteorological Research, 28, 762-779, https://doi.org/10.1007/s13351-0144501-9. 